\title{
Produção e qualidade de pêssegos, cv. Jubileu, com uso de fitorreguladores
}

\author{
Marcos Antônio Giovanaz', José Carlos Fachinello², Carolina Goulart ${ }^{1}$, André Luiz Radünz ${ }^{3}$, \\ Priscila Alvariza Amaral ${ }^{3}$, Diego Weber ${ }^{3}$ \\ http://dx.doi.org/10.1590/0034-737X201461040015
}

\section{RESUMO}

O presente trabalho objetivou avaliar a produção, o retorno da floração e a qualidade físico-química dos frutos de pessegueiro após a utilização de Promalin ${ }^{\circledR}\left(\mathrm{BA}+\mathrm{GA}_{4+7}\right)$ em diferentes doses e épocas de aplicação. O experimento foi realizado no Centro Agropecuário da Palma, na Universidade Federal de Pelotas, no município do Capão do Leão - RS, no ano de 2012. Foram utilizados pessegueiros do cultivar Jubileu, com 13 anos de idade, enxertados sobre o portaenxerto Capdeboscq e com densidade de 1.481 plantas ha- ${ }^{-1}$. Os tratamentos foram: plantas sem aplicação (controle), plantas tratadas com benziladenina $(\mathrm{BA})+$ giberilinas $\left(\mathrm{GA}_{4+7}\right)$ nas doses de 50 e $100 \mathrm{mg} \mathrm{L}^{-1}$, aplicados 10 dias após a plena floração (DAPF) e 30 DAPF. Foram avaliados a produtividade das plantas e os atributos de qualidade físico-química dos frutos. A aplicação do fitorregulador a 30 DAPF resultou em um incremento de $6,62 \mathrm{~kg}$ por planta e proporcionou frutos de maior calibre ( $\geq 65 \mathrm{~mm}$ ); no entanto, não houve diferença estatística entre as doses de 50 e $100 \mathrm{mg} \mathrm{L}^{-1}$. Independentemente das doses utilizadas neste trabalho, a época de aplicação (30 DAPF) foi o fator preponderante para a eficiência dos fitorreguladores no aumento da produção por planta, massa média, diâmetro e firmeza de polpa dos frutos de pessegueiro cv. Jubileu. O número total de gemas floríferas nos ramos é reduzido com a aplicação BA $+\mathrm{GA}_{4+7}$.

Palavras-chave: (Prunus persica (L.) Batsck), Promalin ${ }^{\circledR}$, divisão celular, giberelinas, citocininas.

\section{ABSTRACT}

\section{Effect of plant growth regulators on production and quality of Jubileu peaches}

This study aimed to evaluate the yield, return of flowering and physico-chemical fruit quality of peaches after using Promalin $^{\circledR}\left(\mathrm{BA}+\mathrm{GA}_{4+7}\right)$ at different doses and time of application. The experiment was conducted at Agricultural Center of Palma on Pelotas Federal University, Capão do Leão - RS, in 2012. Peach trees of cultivar Jubileu, 13 years old, grafted on Capdeboscq rootstock, at a density of 1.481 plants ha ${ }^{-1}$ were evaluated. The treatments consisted of: plants without application (control), plants treated with benzyladenine (BA) + gibberellin $\left(\mathrm{GA}_{4+7}\right)$ at the doses 50 and $100 \mathrm{mg}$ $\mathrm{L}^{-1}$, applied at 10 and 30 days after full bloom (DAFB). We evaluated the tree yield, return of flowering and physicochemical quality of fruit. Application of plant growth regulator at 30 DAFB resulted in increase of $6.62 \mathrm{~kg}$ per tree and fruits of larger caliber ( $\geq 65 \mathrm{~mm}$ ), but no significant difference was found between the doses $50 \mathrm{mg} \mathrm{L}^{-1}$ and $100 \mathrm{mg} \mathrm{L}^{-1}$. Regardless of the doses used in this study, the time of application (30 DAFB) was the main factor for the efficiency of the growth regulators in increasing the production per tree, average mass, diameter and pulp firmness of Jubileu peaches . The total number of flowers was reduced with the application of BA $+\mathrm{GA}_{4+7}$.

Key words: Prunus persica, Promalin ${ }^{\circledR}$, cell division, gibberellins, cytokinins.

\footnotetext{
Recebido para publicação em 29/05/2013 e aprovado em 22/07/2013.

${ }^{1}$ Engenheiros-Agrônomos. Departamento de Fitotecnia, Universidade Federal de Pelotas, Caixa Postal 354, 96010-900, Pelotas, Rio Grande do Sul, Brasil. giovanazmarcos@ gmail.com (autor para correspondência); carolina.goulart@yahoo.com.br

${ }^{2}$ Engenheiro-Agrônomo, Doutor. Departamento de Fitotecnia, Universidade Federal de Pelotas, Caixa Postal 354, 96010-900, Pelotas, Rio Grande do Sul, Brasil. jfachi@ ufpel.tche.br ${ }^{3}$ Engenheiros-Agrônomos, Mestres. Departamento de Fitotecnia, Universidade Federal de Pelotas, Caixa Postal 354, 96010-900, Pelotas, Rio Grande do Sul, Brasil. alradunz@yahoo.com.br; prialvariza@gmail.com; dieweb@gmail.com
} 


\section{INTRODUÇÃO}

Os frutos de pêssego ao serem comercializados devem apresentar boa qualidade, sendo essa determinada por um conjunto de características, principalmente pelo tamanho, pela cor, pelo estado fitossanitário e sabor. Frutos com boas características atraem o consumidor, facilitam a comercialização, possibilitam a abertura de novos mercados (Dussi et al., 2006) e, geralmente, proporcionam maior renda ao produtor.

O tamanho dos frutos é determinado pelas características genéticas de cada cultivar e também influenciado por outros fatores de manejo no pomar. Além das práticas já conhecidas e difundidas como poda, raleio, adubação e irrigação, a aplicação de fitorreguladores com o objetivo de aumentar o diâmetro e melhorar o formato dos frutos foi descrita por diversos autores nos últimos anos (Stern et al., 2002; Dabul \& Ayub., 2005; Fauate et al., 2007; Fioravanço et al., 2010 ).

Experimentos com frutíferas de clima temperado utilizando citocininas sintéticas demonstraram que o nível endógeno nas plantas é um fator importante e que pode limitar o crescimento e o tamanho final dos frutos (Greene, 1995; Stern \& Flaishman, 2003; Stern et al., 2006). A aplicação exógena de citocinina nas plantas proporcionou incremento de tamanho em maçãs (Stern et al., 2006), peras (Stern et al., 2002), uvas (Reynolds et al., 1992) e kiwis (Famiani et al., 1999).

Segundo Jackson (2003), as giberilinas (GA) influenciam no tamanho dos frutos de maçãs e peras por meio do crescimento celular. Sua utilização foi demonstrada quando a aplicação localizada de $\mathrm{GA}_{4}$ ou $\mathrm{GA}_{7}$ em um dos lados dos frutos resultou em aumento celular, produzindo frutos assimétricos (Bukovac \& Nakawaga, 1968). Mais recentemente, Curry (2012) observou por microscopia de varredura aumento na densidade celular na epiderme de frutos de macieira tratados com aplicações de $\mathrm{GA}_{4+7}$, a qual diminuiu a incidência de russeting nos frutos.

A combinação de citocininas e giberilinas na fruticultura apresenta respostas e funcionalidades diferentes, dependendo da cultura e época de aplicação. Em pessegueiro foi observado o favorecimento do crescimento de ramos laterais (Rufato et al., 2004), o aumento no pedicelo de frutos de macieira (Dabul \& Ayub, 2005), o aumento da frutificação efetiva em peras (Dussi, 2011) e a melhora do formato e tamanho dos frutos de maçãs e peras (Leite et al., 2006; Dussi, 2011).

O presente trabalho objetivou avaliar a produção e a qualidade físico-química dos frutos de pessegueiro, cv. Jubileu, após a utilização de BA $+\mathrm{GA}_{4+7}\left(\right.$ Promalin $\left.^{\circledR}\right)$ em diferentes doses e épocas de aplicação.

\section{MATERIAL E MÉTODOS}

O experimento foi conduzido no Centro Agropecuário da Palma, na Universidade Federal de Pelotas, localizada no município do Capão do Leão - RS, durante a safra $2012 / 2013$. Foram utilizados pessegueiros cultivar Jubileu, com 13 anos de idade, enxertados sobre o portaenxerto Capdeboscq. A densidade do pomar é de 1.481 plantas ha $^{-1}$, com espaçamento de 4,5 m entre linhas e 1,5 m entre plantas e conduzidas em sistema de vaso.

$\mathrm{O}$ experimento consistiu de cinco tratamentos, sendo eles: plantas sem aplicação (controle), plantas tratadas com benziladenina (BA) + giberilinas $\left(\mathrm{GA}_{4+7}\right)$ nas doses de 50 (3,38 $\mathrm{L} \mathrm{ha}^{-1}$ do produto comercial) e $100 \mathrm{mg} \mathrm{L}^{-1}(6,76$ $\mathrm{L} \mathrm{ha}^{-1}$ do produto comercial), aplicados 10 dias após a plena floração (DAPF) e 30 DAPF. As aplicações das diferentes doses foram realizadas por aspersão, utilizando pulverizador costal com volume médio de calda de aproximadamente 1.270 $\mathrm{L} \mathrm{ha}^{-1}$. Como fonte de $\mathrm{BA}+\mathrm{GA}_{4+7}$ foi usado o produto Promalin ${ }^{\circledR}$ contendo $1,88 \%$ de cada ingrediente ativo (1:1). Em todos os tratamentos foi adicionado óleo mineral (Assist ${ }^{\circledR}$ ) a $0,2 \%$.

Para as avaliações foram colhidos aleatoriamente 40 frutos por repetição, e calculada a massa média de fruto $(\mathrm{g})$, produção por planta $(\mathrm{kg} /$ planta) e produtividade $(\mathrm{t}$ $\left.\mathrm{ha}^{-1}\right)$. Foi determinado o diâmetro médio dos frutos ( $\mathrm{mm}$ ), que foram divididos em três classes, $47 \geq 57 \mathrm{~mm}$, de $57>$ $65 \mathrm{~mm} \mathrm{e} \geq 65 \mathrm{~mm}$. A firmeza dos frutos foi determinada com penetrômetro digital de bancada Turoni 53205, utilizando-se ponteira de $8 \mathrm{~mm}$ de diâmetro, após retirada da casca nas duas faces opostas da região equatorial, e expressa em Newtons (N). O teor de sólidos solúveis (SS) foi determinado utilizando-se refratômetro digital e expresso em ${ }^{\circ}$ Brix. A acidez titulável (AT) foi quantificada por neutralização da acidez de $10 \mathrm{~mL}$ de amostra (suco) em 90 $\mathrm{mL}$ de água destilada com $\mathrm{NaOH} 0,1 \mathrm{~N}$ até $\mathrm{pH} 8,1$, e expressa em miliequivalente (meq $100 \mathrm{~mL}^{-1}$ ).

No ano de 2013, após a queda das folhas do pessegueiro, foi avaliado o retorno da floração, o qual foi expresso em número de gemas floríferas por centímetro de ramo. Para tanto, foram marcados oito ramos por planta, dois por cada quadrante da planta, contando-se o número de gemas floríferas e medindo-se o tamanho dos ramos.

O delineamento experimental foi um fatorial 2 × 2 com testemunha adicional em blocos ao caso. Foram utilizadas três repetições de três plantas por parcela, avaliando-se a planta central. Os resultados obtidos foram submetidos à análise de variância $(\mathrm{p} \leq 0,05)$, sendo a testemunha repetida no fator época para análise de interação entre os fatores. Quando a análise da variância indicou efeitos significativos dos fatores em estudo foram realizadas comparações de médias, empregando-se o teste de Duncan ( $\mathrm{p} \leq 0,05)$. 


\section{RESULTADOS}

Os tratamentos realizados com $\mathrm{BA}+\mathrm{GA}_{4+7}$ aumentaram a massa média dos frutos do cultivar. Com exceção da dose $100 \mathrm{mg} \mathrm{L}^{-1}$ aplicada aos $10 \mathrm{DAPF}$, todos os tratamentos foram estatisticamente significativos e promoveram incremento na massa média dos frutos em relação ao controle. A dose de $100 \mathrm{mg} \mathrm{L}^{-1}$ a 30 DAPF foi a que proporcionou a maior massa média e resultou em incremento de 34 g por fruto, seguida pela dose de $50 \mathrm{mg} \mathrm{L}^{-1}$ a $30 \mathrm{DAPF}$, que proporcionou aumento de $21 \mathrm{~g}$ por fruto.

Na produção por planta, os tratamentos realizados a 30 DAPF foram significativamente superiores aos demais, independentemente das doses utilizadas. A aplicação de $\mathrm{BA}+\mathrm{GA}_{4+7}$ resultou em incremento de $6,62 \mathrm{~kg}$ por planta para a dose de $50 \mathrm{mg} \mathrm{L}^{-1}$ e de 7,01 kg para a dose de $100 \mathrm{mg}$ $\mathrm{L}^{-1}$ em relação à testemunha. Os tratamentos aplicados a 10 DAPF não apresentaram diferença significativa quando comparados ao tratamento controle (Tabela 1).

Os frutos de pessegueiros foram divididos em três classes de diâmetro. Na menor delas, entre $47 \geq 57 \mathrm{~mm}$, as aplicações efetuadas a 30 DAPF apresentaram a menor porcentagem de frutos de menor calibre, $3,3 \%$ para a dose de $50 \mathrm{mg} \mathrm{L}^{-1}$ e $5,67 \%$ para $100 \mathrm{mg} \mathrm{L}^{-1}$. Nas aplicações realizadas a $10 \mathrm{DAPF}$, a porcentagem de frutos menores foi semelhante ao controle, não apresentando diferença significativa. Nos frutos classificados como medianos (57 $\leq$ $65 \mathrm{~mm}$ ) não foi observada diferença significativa entre os tratamentos. Já para os frutos classificados como grandes (> $65 \mathrm{~mm}$ ), foi possível verificar maior efeito dos tratamentos aplicados a 30 DAPF. As doses de $50 \mathrm{mg} \mathrm{L}^{-1} \mathrm{e} 100$ $\mathrm{mg} \mathrm{L}^{-1}$ aplicadas a 30 DAPF representaram, respectivamente incremento de $37,66 \%$ e 34,66\% em relação ao controle, no entanto, não foi observada diferença significativa entre as doses (Tabela 1).

Observou-se incremento do diâmetro médio dos frutos, acompanhado pelo aumento da produtividade, com a aplicação do regulador vegetal realizada aos 30 DAPF (Figura 1). As aplicações efetuadas aos 10 DAPF não diferiram estatisticamente do controle.

A firmeza de polpa das frutas tratadas aos $10 \mathrm{DAPF}$ não diferiu estatisticamente do controle. Já as doses aplicadas aos 30 DAPF proporcionaram frutos com maior firmeza de polpa que os demais tratamentos. No que se refere ao teor de sólidos solúveis (SS) e acidez titulável (AT), não foram observadas diferenças significativas com a aplicação do fitorregulador (Tabela 2).

$\mathrm{A}$ aplicação de $\mathrm{BA}+\mathrm{GA}_{4+7}$ proporcionou redução significativa, no ciclo seguinte, no número de gemas de flor por centímetro de ramo em relação ao controle, porém não apresentou diferença entre as doses e datas de aplicação (Tabela 3).

\section{DISCUSSÃO}

O intervalo de tempo para a aplicação dos fitorreguladores após a floração do pessegueiro pode ser determinante para que os reguladores vegetais possam atuar no aumento da massa média e no diâmetro médio dos frutos. Segundo Pavel \& DeJong (1993), o crescimento dos frutos de pessegueiro é limitado em períodos específicos e ocorrem variações na taxa de crescimento dos frutos durante o seu desenvolvimento. Jackson (1968) evidenciou flutuação da quantidade de giberelinas durante o desenvolvimento de pêssegos no pericarpo, mesocarpo e endocarpo. Esses fatos podem sugerir que no momento da aplicação aos 30 DAPF os frutos poderiam estar em fase de maior divisão celular, ocorrendo maior metabolização e aproveitamento da citocinina e das giberelinas, uma vez que a presença de um hormônio em um órgão da planta, como o fruto, pode atrair metabólitos, água e minerais, determinando a capacidade desse órgão em competir por esses nutrientes (Jackson, 1968).

Tabela 1. Efeito de BA $+\mathrm{GA}_{4+7}$ na massa média dos frutos, produção por planta e no diâmetro dos frutos de pessegueiro 'Jubileu' divididos em classes

\begin{tabular}{|c|c|c|c|c|c|c|c|}
\hline \multicolumn{3}{|c|}{ Tratamentos } & \multirow{2}{*}{$\begin{array}{c}\text { Massa média } \\
\text { (g) }\end{array}$} & \multirow{2}{*}{$\begin{array}{c}\text { Produção } \\
\left(\text { kg planta }^{-1}\right)\end{array}$} & \multicolumn{3}{|c|}{ Classes (\%) } \\
\hline & $\begin{array}{c}\text { Doses } \\
\left(\mathbf{m g} \mathbf{L}^{-1}\right)\end{array}$ & DAPF & & & $47>57 \mathrm{~mm}$ & $57>65 \mathrm{~mm}$ & $\geq 65 \mathrm{~mm}$ \\
\hline Controle & - & - & $129 \mathrm{~d}^{1}$ & $22,9 \mathrm{~b}$ & $27,0 \mathrm{a}$ & $55,3^{\mathrm{ns}}$ & $17,6 \mathrm{~b}$ \\
\hline $\mathrm{BA}+\mathrm{GA}_{4+7}$ & $50+50$ & 10 & $138 \mathrm{c}$ & $23,3 \mathrm{~b}$ & $19,0 \mathrm{a}$ & 49,3 & $31,6 \mathrm{~b}$ \\
\hline $\mathrm{BA}+\mathrm{GA}_{4+7}$ & $100+100$ & 10 & $136 \mathrm{dc}$ & $23,3 \mathrm{~b}$ & $20,3 \mathrm{a}$ & 57,3 & $22,3 \mathrm{~b}$ \\
\hline $\mathrm{BA}+\mathrm{GA}_{4+7}$ & $50+50$ & 30 & $150 \mathrm{~b}$ & $29,5 \mathrm{a}$ & $3,3 \mathrm{~b}$ & 41,3 & 55,3 a \\
\hline $\mathrm{BA}+\mathrm{GA}_{4+7}$ & $100+100$ & 30 & $163 \mathrm{a}$ & $29,9 \mathrm{a}$ & $5,67 \mathrm{~b}$ & 42,0 & $52,3 \mathrm{a}$ \\
\hline DAPF & - & - & $* * *$ & $* * *$ & $* * *$ & ns & $* *$ \\
\hline Doses & - & - & $* * *$ & $* * *$ & $* *$ & ns & $* *$ \\
\hline DAPF x Doses & - & - & $* * *$ & $* * *$ & $*$ & ns & $*$ \\
\hline
\end{tabular}

${ }^{1}$ Médias seguidas de letras minúsculas iguais na coluna não diferem entre si pelo teste de Duncan a 5\% de probabilidade. ns, *, **, ***: não significativos, ou significativos em $\mathrm{P}<0,05,0,01$ e 0,001 , respectivamente. DAPF: dias após a plena floração. 
A dose de $100 \mathrm{mg} \mathrm{L}^{-1}$ proporcionou efeito semelhante na produção por planta à dose de $50 \mathrm{mg} \mathrm{L}^{-1}$, evidenciando que o efeito do produto é mais dependente da época de aplicação do que da dose utilizada. Em macieiras 'Royal Gala', Fioravanço et al. (2010) aplicaram BA + $\mathrm{GA}_{4+7}$ em duas épocas (plena floração e queda das pétalas) em quatro doses no ano de 2007, e obtiveram frutos com maior diâmetro e comprimento quando o produto foi aplicado na queda das pétalas. $\mathrm{O}$ aumento do diâmetro dos frutos não foi proporcional ao da dose, sendo o maior diâmetro obtido na dose de 2,0 $\mathrm{ml} \mathrm{L}^{-1}$ de $\operatorname{Promalin}^{\circledR}\left(\mathrm{BA}+\mathrm{GA}_{4+7}\right)$.

$\mathrm{O}$ aumento na massa dos frutos obtida neste experimento com a aplicação de $\mathrm{BA}+\mathrm{GA}_{4+7}$ está de acordo com resultados encontrados por outros autores, trabalhando com outras espécies. Fauate et al. (2007) observaram au- mento na massa de caquis 'Fuyu' com a aplicação na plena floração e obtiveram na dose de 2,79 $\mathrm{L} \mathrm{ha}^{-1}$ de Promalin ${ }^{\circledR}$ os melhores resultados. Dabul \& Ayub (2005) obtiveram aumento de 27,93 g na massa dos frutos de maçãs 'Gala' com aplicação de $\mathrm{BA}+\mathrm{GA}_{4+7}$; no entanto, os mesmos autores Dabul \& Ayub (2006), em outro experimento, não obtiveram resultados positivos em maçãs 'Gala', o que torna os resultados variados.

Apesar dos tratamentos 50 e $100 \mathrm{mg} \mathrm{L}^{-1}$ aplicados a 30 DAPF apresentarem diferença estatística para a massa média dos frutos, o mesmo não foi observado para produção por planta. Quando o raleio é mais intenso, a competição por carboidratos entre os frutos é menor, o que ocasiona sua melhor distribuição e proporciona frutos maiores (Byers et al., 2003).

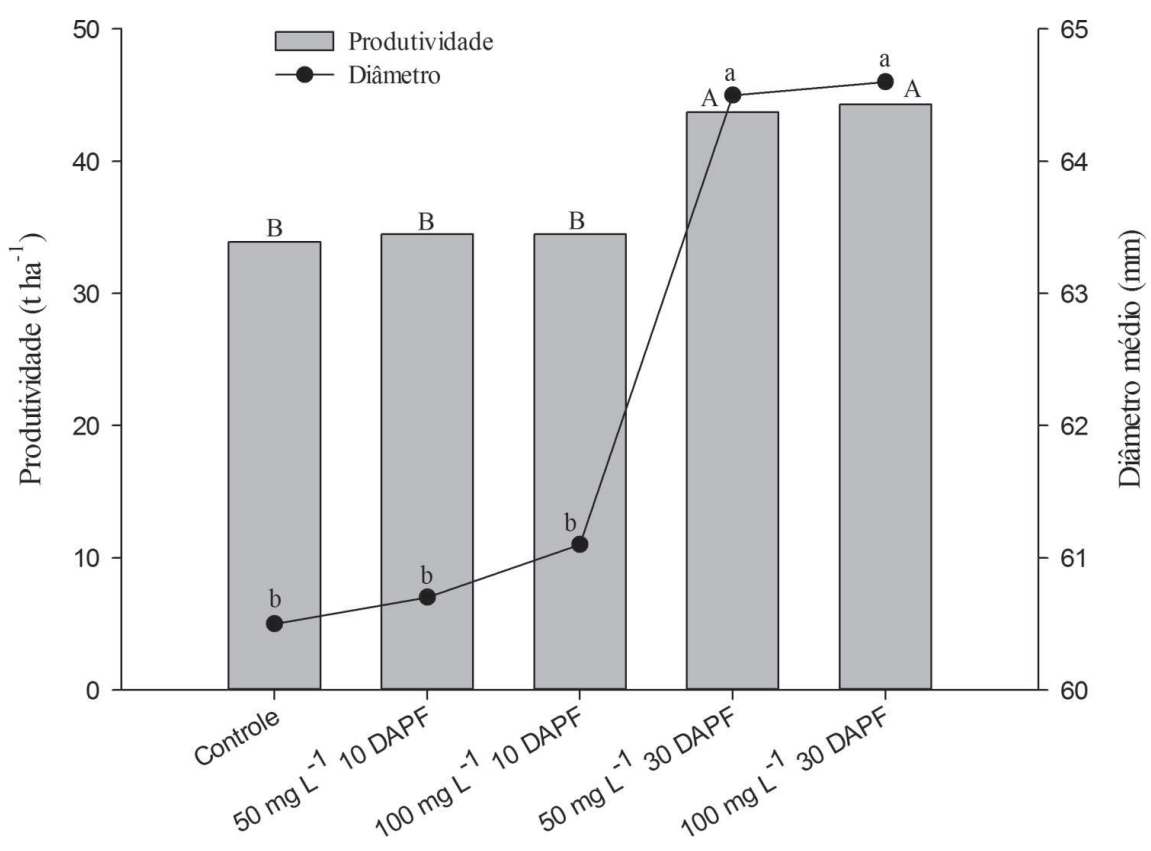

Figura 1. Produtividade $\left(\mathrm{t} \mathrm{ha}^{-1}\right)$ e diâmetro médio $(\mathrm{mm})$ dos frutos de pessegueiro 'Jubileu' após a aplicação de $\mathrm{BA}+\mathrm{GA}_{4+7} \mathrm{em}$ épocas distintas. Médias seguidas de letras minúsculas iguais na linha e maiúsculas nas barras não diferem entre si pelo teste de Duncan a $5 \%$ de probabilidade.

Tabela 2. Efeito de BA $+\mathrm{GA}_{4+7}$ na firmeza de polpa, sólidos solúveis (SS) e na acidez titulável (AT) dos frutos de pessegueiro 'Jubileu'

\begin{tabular}{|c|c|c|c|c|c|}
\hline \multicolumn{3}{|c|}{ Tratamentos } & \multirow{2}{*}{ Firmeza (N) } & \multirow{2}{*}{ SS $\left({ }^{\circ}\right.$ Brix $)$} & \multirow{2}{*}{$\operatorname{AT}\left(\operatorname{meq} 100 \mathrm{~mL}^{-1}\right)$} \\
\hline & Doses (mg L L $\left.\mathbf{~}^{-1}\right)$ & DAPF & & & \\
\hline Controle & - & - & $15,2 b^{1}$ & $13,8^{\mathrm{ns}}$ & $11,0^{\mathrm{ns}}$ \\
\hline $\mathrm{BA}+\mathrm{GA}_{4+7}$ & $50+50$ & 10 & $16,6 \mathrm{~b}$ & 13,6 & 10,7 \\
\hline $\mathrm{BA}+\mathrm{GA}_{4+7}$ & $100+100$ & 10 & $14,8 \mathrm{~b}$ & 13,4 & 10,2 \\
\hline $\mathrm{BA}+\mathrm{GA}_{4+7}$ & $50+50$ & 30 & $19,7 \mathrm{a}$ & 13,3 & 11,1 \\
\hline $\mathrm{BA}+\mathrm{GA}_{4+7}$ & $100+100$ & 30 & $20,9 \mathrm{a}$ & 14,7 & 11,5 \\
\hline DAPF & - & - & $*$ & $\mathrm{~ns}$ & $\mathrm{~ns}$ \\
\hline Doses & - & - & $* *$ & $\mathrm{~ns}$ & $\mathrm{~ns}$ \\
\hline DAPF x Doses & - & - & $*$ & $\mathrm{~ns}$ & $\mathrm{~ns}$ \\
\hline
\end{tabular}

${ }^{1}$ Médias seguidas de letras minúsculas iguais na coluna não diferem entre si pelo teste de Duncan a 5\% de probabilidade. ns, *, **, ***: não significativos, ou significativos em $\mathrm{P}<0,05,0,01$ e 0,001, respectivamente. DAPF: dias após a plena floração. 
Tabela 3. Retorno da floração do pessegueiro 'Jubileu' após aplicação de BA + GA ${ }_{4+7}$ em 2012

\begin{tabular}{lcccc}
\hline & Tratamentos & DAPF & $\begin{array}{c}\text { Retorno da floração } \\
\text { (gemas floríferas } \\
\mathbf{c m}^{-1} \text { de ramo) }\end{array}$ & $\begin{array}{c}\text { Redução na } \\
\text { quantidade de } \\
\text { gemas(\%) }\end{array}$ \\
\hline Doses $\left(\mathbf{m g ~ L}^{-1}\right)$ & & & - \\
Controle & - & - & $0,93 \mathrm{a}^{1}$ & $8,6 \%$ \\
$\mathrm{BA}+\mathrm{GA}_{4+7}$ & $50+50$ & 10 & $0,85 \mathrm{ab}$ & $19,3 \%$ \\
$\mathrm{BA}+\mathrm{GA}_{4+7}$ & $100+100$ & 10 & $0,75 \mathrm{~b}$ & $16,1 \%$ \\
$\mathrm{BA}+\mathrm{GA}_{4+7}$ & $50+50$ & 30 & $0,78 \mathrm{~b}$ & $17,2 \%$ \\
$\mathrm{BA}+\mathrm{GA}_{4+7}$ & $100+100$ & 30 & $0,77 \mathrm{~b}$ & - \\
DAPF & - & - & $\mathrm{ns}$ & - \\
Doses & - & - & $*$ & $\mathrm{~ns}$ \\
DAPF x Doses & - & - & & - \\
\hline
\end{tabular}

${ }^{1}$ Médias seguidas de letras minúsculas iguais na coluna não diferem entre si pelo teste de Duncan a $5 \%$ de probabilidade. ns, $*, * *$, ***: não significativos, ou significativos em $\mathrm{P}<0,05,0,01$ e 0,001, respectivamente. DAPF: dias após a plena floração.

A combinação dos fitorreguladores proporcionou aumento dos frutos tipo I, classificados pela indústria $\geq 57$ mm de diâmetro, podendo gerar maior renda final ao produtor. Stern (2008) observou que a combinação da citocinina (BA) com as giberilinas $\left(\mathrm{GA}_{4+7}\right)$, cada uma com dose de $25 \mathrm{mg} \mathrm{L}^{-1}$ aplicadas a $14 \mathrm{DAPF}$, aumentou o tamanho de peras 'Spadona' e 'Coscia' sem causar deformação dos frutos. Dabul \& Ayub (2005) relataram aumento de 5,45 mm no diâmetro dos frutos de maçã 'Gala' e Fauate et al. (2007) observaram que a aplicação de BA + $\mathrm{GA}_{4+7}$ promoveu aumento quadrático no diâmetro de fruto de caquis 'Fuyu'.

A firmeza de polpa dos frutos, ao contrário do relatado por outros autores, aumentou com a aplicação de BA + $\mathrm{GA}_{4+7}$ aos 30 DAPF. Trabalhando com maçãs 'Gala', Dabul \& Ayub (2005) não observaram alterações na firmeza de polpa dos frutos, sendo o mesmo verificado por Fauate et al. (2007) em caquis 'Fuyu'. Southwick et al. (1995) obtiveram maior firmeza de polpa nos frutos com maior diâmetro, e associaram o aumento da firmeza à maior relação da parede celular com o volume da célula, visto que frutos maiores possuem maior quantidade de células que os menores (Westwood et al., 1967; Ho, 1988). Greene (1993), em uma revisão sobre BA, sugere que o incremento da firmeza dos frutos se deva ao aumento da divisão celular promovido pela citocinina e, consequentemente, a um maior número de células.

O teor de sólidos solúveis e a acidez titulável em plantas submetidas à aplicação dos fitorreguladores não diferiu de os do tratamento controle. Fauate et al. (2007) também não observaram mudança no conteúdo de sólidos solúveis de caqui 'Fuyu' após aplicação de BA $+\mathrm{GA}_{4+7} \mathrm{e}$ em maçãs 'Gala'; Dabul \& Ayub (2005) não verificaram efeito nos sólidos solúveis.

A redução, no ciclo seguinte, do número de gemas floríferas dos ramos possivelmente esteja relacionada com o momento da aplicação do fitorregulador, podendo os primórdios vegetativos dos ramos em desenvolvimento estarem no período indutivo. A aplicação de giberilinas durante o período de indução floral pode inibir a iniciação floral e diminuir o número de flores na safra seguinte (Southwick \& Glozer, 2000). A aplicação de giberelinas como o ácido giberélico está sendo investigada com o intuito de diminuir o tempo de raleio manual em frutíferas de caroço pela redução do número de flores (Southwick \& Glozer, 2000; Stern \& Bem-Arie, 2009). Provavelmente a redução do número de gemas floríferas nos ramos de pessegueiro do cultivar Jubileu não foi expressiva a ponto de comprometer a produção do ano seguinte; no entanto, essa redução pode contribuir para diminuir a mão de obra do raleio na safra seguinte.

\section{CONCLUSÕES}

Independentemente das doses utilizadas neste traba1ho, a época de aplicação (30 DAPF) foi o fator preponderante para a eficiência dos fitorreguladores no aumento da produção por planta, massa média, diâmetro e firmeza de polpa dos frutos de pessegueiro cv. Jubileu.

Os sólidos solúveis e a acidez titulável de pêssegos 'Jubileu' não são alterados após a aplicação de BA + GA 4+7. $_{\text {. }}$

A aplicação de $\mathrm{BA}+\mathrm{GA}_{4+7}$ a 10 e $30 \mathrm{DAPF}$ provoca redução no número de gemas florais para a safra seguinte

\section{REFERENNCIAS}

Byers RE, Costa G \& Vizzotto G (2003) Flower and fruit thinning of Peach and other Prunus. Horticultural Reviews, 28:351-392.

Bukovac MJ \& Nakagawa S (1968) Gibberellin-induced asymmetric growth of apple fruits. HortScience, 3:172-173.

Curry E (2012) Increase in Epidermal Planar Cell Density Accompanies Decreased Russeting of 'Golden Delicious' Apples Treated with Gibberellin $\mathrm{A}_{4+7}$. Hortscience, 47:232-237. 
Dabul ANG \& Ayub RA (2005) Efeito da aplicação de Promalin® em frutos de maçã (Malus domestica) cv. Gala. Revista Ceres, 52:351-356.

Dabul ANG \& Ayub RA (2006) Efeito da promalina (6BA+GA4+7) no crescimento e no desenvolvimento de frutos de macieira (Malus domestica, Borkh.) cv. Gala. Revista Semina: Ciências Agrárias, 27:199-203.

Dussi MC, Giardina G, Reeb P, Bernardin F \& Apendino E (2006) Fruit thinning effects in the apple cv. 'Royal Gala'. Acta Horticulturae, 727:401-408

Dussi MC (2011) Sustainable use of plant bioregulators in pear production. Acta Horticulturae, 909:353-368.

Famiani F, Battistelli A, Moscatello S, Boco M \& Antognozzi E (1999) Thidiazuron affects fruit growth, ripening and quality of Actinidia deliciosa. The Journal of Horticultural Science and Biotechnology, 74:375-380.

Fauate A, Fauate M, Ayub RA \& Marlgarin MB (2007) Aplicação de $\mathrm{GA}_{4,7}+\mathrm{BA}$ (promalina) afetando o crescimento, desenvolvimento e qualidade do caqui (Diospyros kaki 1.) cv. Fuyu. Revista Ceres, 54:225-229.

Fioravanço JC, Almeida GK \& Silva VC (2010) Efeito da Promalina ${ }^{\circledR}\left(\mathrm{GA}_{4+7}+6 \mathrm{BA}\right)$ na produção e desenvolvimento dos frutos da macieira cv. Royal Gala. Revista de Ciências Agroveterinárias, 9:143-149.

Greene WDA (1993) review of the use of benzyladenine (BA) as a chemical thinners for apples. Acta Horticulturae, 329:231-236.

Greene DW (1995) Thidiazuron effects on fruit set, fruit quality, and return bloom of apples. HortScience, 30:1238-1240.

Ho LC (1988) Metabolism and compartmetation of imported sugars in sink organs in relation to sink strength. Annual Review of Plant Physiology and Plant Molecular Biology, 39:355-378.

Jackson DI (1968) Gibberellin and the growth of peach and apricots fruits. Australian Journal of Biological Sciences, 21:209-215.

Jackson J (2003) Biology of Apples and Pears. Nova York, Cambridge University Press. 488p.

Leite GB, Petri JL \& Basso C (2006) Promalin effect on 'Imperial Gala' and 'Fuji' apples trees fructification. Acta Horticulturae, 727:269-278

Pavel EW \& DeJong TM (1993) Source- and sink- limited growth periods of developing peach fruits indicated by relative growth rate analysis. Journal of the American Society for Horticultural Science, 118:820-824.
Reynolds AG, Wardle DA, Zurowski C \& Looney NE (1992) Phenylureas CPPU and thidiazuron affect yield components, fruit composition, and storage potential of 4 seedless grape selections. Journal of the American Society for Horticultural Science, 117:85-89.

Rufato LDE, Rossi A \& Faria JLC (2004) Uso de promalina e incisão anelar no incremento do crescimento vegetativo de ramos laterais em pessegueiro (Prunus pérsica (L) BATSCH) conduzidos em axis colunar. Revista Brasileira de Agrociência, 10:117-122.

Stern RA, Flaishman M \& Shargal A (2002) Effect of the synthetic cytokinin CPPU on fruit size and yield of 'Spadona' pear. Acta Horticulturae, 596:797-801.

Stern RA \& Flaishman M (2003) Benzyladenine effects on fruit size, fruit thinning and return yield of 'Spadona' and 'Coscia' pear. Scientia Horticulturae, 98:499-504.

Stern RA, Ben-Arie R, Applebaum S \& Flaishman M (2006) Cytokinins increase fruit size of 'Delicious' and 'Golden Delicious' (Malus domestica) apple in a warm climate. The Journal of Horticultural Science and Biotechnology, 81:51-56.

Stern RA (2008) Increasing fruit size of 'Spadona' and 'Coscia' (Pyrus communis) pears in a warm climate with plant growth regulators. Acta Horticulturae, 800:155-162.

Stern RA \& Ben-Arie R (2009) GA3 Inhibitis flowering, reduces hand-thinning, and increases fruit size in peach and nectarine. Journal of Horticultural Science \& Biotechnology, 84:119-124.

Southwick SM, Weis KG, Yeager JT \& Zhou H (1995) Controlling Cropping in 'Loadel' Cling Peach Using Gibberellin: Effects on Flower Density, Fruit Distribution, Fruit Firmness, Fruit Thinning, and Yield. Journal of the American Society for Horticultural Science, 120:1087-1095.

Southwick SM \& Glozer K (2000) Reducing flowering with gibberellins to increase fruit size in stone fruit trees: Applications and implications in fruit production. HortTechnology, 10:744751.

Westwood MN, Batjer LP \& Billingsley HD (1967) Cell size, cell number, and fruit density of apples as related to fruit size, position in cluster, and thinning method. Proceedings of the American Society for Horticultural Science, 91:51-62. 